\title{
Is Primary Fixation with the Sliding Hip Screw Introduced into the Non-ideal Position Sufficient for Stable Pertrochanteric Fracture Stabilisation? A Biomechanical Evaluation and Experimental Study
}

\author{
Libor Nečas', Maroš Hrubinaa,2*, Marian Melišík1, Zoltán Cibula1', Deniz Z. Olgun³, Zdeněk Horák ${ }^{4}$ \\ ${ }^{1}$ Orthopaedic Clinic, Jessenius Faculty of Medicine in Martin Comenius University in Bratislava and University Hospital Martin, \\ Kollarova 2, Martin, 036 59, Slovak Republic \\ 2 Department of Orthopaedics, Hospital Pelhrimov, Slovanskeho bratrstvi 710, Pelhrimov, 393 01, Czech Republic \\ ${ }^{3}$ Department of Orthopaedics, Children's Hospital of Pittsburgh of UPMC, 4401 Penn Ave, Pittsburgh, USA \\ ${ }^{4}$ Department of Technical Studies, College of Polytechnics Jihlava, Tolsteho 16, Jihlava, 586 01, Czech Republic \\ *Corresponding author, e-mail: mhrubina@gmail.com
}

Received: 06 October 2018, Accepted: 18 October 2018, Published online: 25 February 2019

\begin{abstract}
Purpose: Proximal femoral fractures are most commonly sustained fractures in the elderly. The one of the current treatment option of stable pertrochanteric fracture is Sliding Hip Screw. The necessity of a repeat surgery, due to the failure of the first osteosynthesis, may jeopardize the patient's life. Common causes of a failure include: fracture pattern, implant position, implant's properties and the bone quality. Each screw position variant results in damage to various load-bearing bone structures during healing. The aim of this study was analysis of different screw positions with focuse on the risky position with the need of the intra-operative implant reintroduction. Methods: With the use of a numerical computational model and finite element methods, the authors analyzed five positions of Sliding Hip Screw in the proximal femur, with the objective of determining positions with an increased risk of failure. The ideal position was in the middle third of the femoral neck anchored subchondrally.

Results: In model situations, it has been shown that in stable fractures the screw position in proximal third of the femoral neck significantly increased the strain of the plate and screw and may lead to the osteosynthesis failure. The other analysed positions do not significantly increase the risk of failure for entire fixation.

Conclusions: It is not necessary to re-introduce Sliding Hip Screw into the ideal position (except placening in the proximal third of the neck) during the surgery. Damage to load-bearing structures relative to various implant placements does not impact the resultant overall fixation stability.
\end{abstract}

Keywords

Sliding Hip Screw, proximal femoral fractures, complications, FE analyses

\section{Introduction}

The frequency of proximal femoral fractures has been on an upward swing due to an increase of the geriatric population $[1,2]$. Technological and material developments have provided two groups of implants, extramedullary and intramedullary, the use of which is hoped to facilitate the healing of these types of fractures. Osteosynthesis with the use of the Sliding Hip Screw (SHS) is a method employed in the treatment of stable proximal femoral fractures. It is a relatively simple and reliable method, and often one of the earliest fracture fixations performed by orthopaedic surgeons in training. The biomechanical principle of the SHS is stable contact of the femoral fragments and controlled impaction during fracture healing with the screw sliding inside the plate, which contributes to axial and torsional stability in addition to compressive capability. In this "ideal" situation, the cancellous and cortical bone contact of both femoral fragments is acquired and maintained by the SHS for the period of time until fracture healing. While conceptually straightforward, reported revision rates with this implant are between $4 \%$ to $12 \%$ [3]. Successful treatment 
with the SHS is influenced by a variety of factors. These primarily include the general condition of the patient, fracture pattern and bone quality. Technical errors can lead to failure as well [4]. The optimal position of the SHS has been researched previously, and the tip-apex distance (TAD) found to be an accurate predictor of lag screw cutout [5]. Furthermore, previous research also indicates that a center-center positioning of the SHS in both planes is beneficial and should be striven for during surgery. However, fracture surgery is not an exact science, and many times, unintended malposition of the lag screw can be noticed intraoperatively due to a number of reasons, among them technical difficulties and surgeon inexperience. The senior surgeon is then left with a dilemma: accept the non-ideal position, or remove the lag screw, leaving behind a large screw track in a patient with already deficient bone stock, and reintroduce it in a better position.

The hypothesis of this experimental study is that some "non-ideal" positions of the SHS are acceptable from a biomechanical point of view. The aim of this study is to answer the question of which non-ideal SHS positions are tolerable, as in sufficient for fracture fixation, and which ones should be changed intra-operatively based on a finite element model.

\section{Materials and methods}

Finite Element Method Analysis (FE): The finite element method was used to analyze the responses of femoral bone and SHS to external loads. These analyses were performed on a stable pertrochanteric fracture model (AO/OTA 31A1) of the femur (Fig. 1), with the SHS in five different theoretical positions (Fig. 2).

All five analyzed SHS positions have been seen to occur in clinical practice. In biomechanical simulations, the same model with the same background (loading, interactions, boundary conditions, etc.) was utilized. Only the position of the hip screw in the anteroposterior plane was altered (Fig. 3). In the axial plane, the screw position remained centrally for each model (Fig. 4).

Each single FE model represented one unique theoretical position of the SHS for fracture fixation.

Anatomy of the stable proximal femoral fracture: Proximal femoral model analysed had a neck-shaft angle (collum-diaphysis angle) of $135^{\circ}$ and the femoral neck with $15^{\circ}$ of anteversion. The stable pertrochanteric fracture created included a fracture line extending just above the trochanter minor, ventrally in the area of linea intertrochanterica, with the following reference points: one

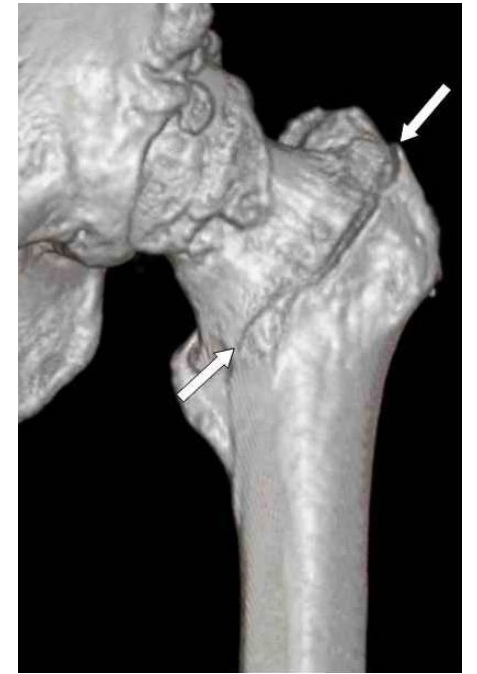

Fig. 1 CT scan of a 58-year old male patient reveals a left femur with a stable pertrochanteric fracture similar to the FE analysis model. Arrows indicate fracture line.

a)

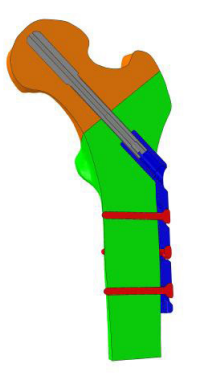

b)

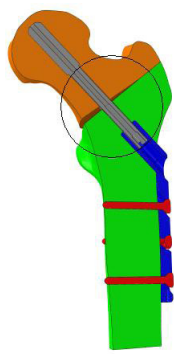

c)

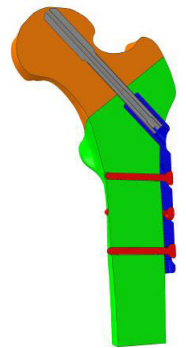

d)

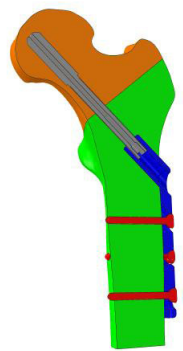

e)

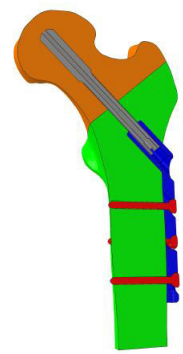

Fig. 2 Analyzed models based on the location of the lag screw in the anteroposterior plane in the femoral neck. a) the "ideal" position of lag screw in the middle third of the femoral neck, which corresponds to Model I. b) displaced fracture line medially leaving a gap between fragments, (indicated by circle) which corresponds to Model II. c) placement of the screw in the superior third of the femoral neck which corresponds to Model III. d) placement of the screw in the inferior third of the femoral neck which corresponds to Model IV. e) the lag screw not anchored subchondrally, which corresponds to Model V.

third of the distance between tuberculum trochantericum and tuberculum innominatum, dorsally in the area of crista intertrochanterica; and with the possibility of the opening the fracture line medially into the Adams arch (Model II). This two-fragment fracture pattern 


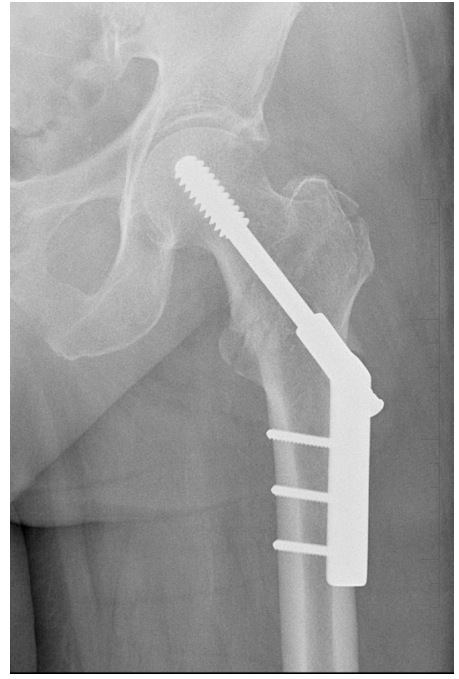

Fig. 3 Postoperative anteroposterior radiograph of a stable pertrochanteric femoral fracture treated with the Sliding Hip Screw

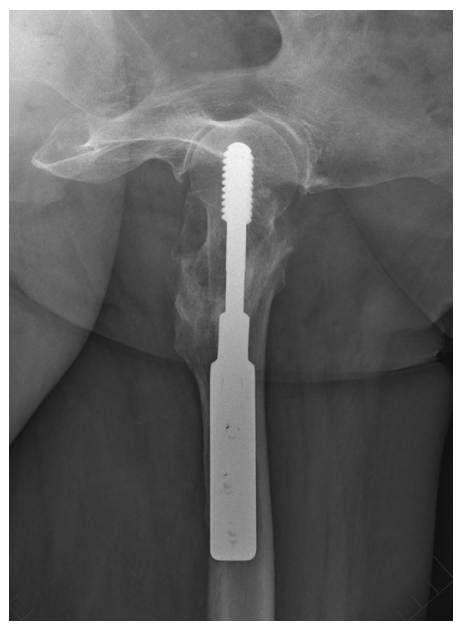

Fig. 4 Axial radiograph of the other patient demonstrating screw placement centrally in the femoral neck and caput femoris

(AO/OTA 31A1) is characterized with sufficient bony contact between fracture fragments after adequate reduction of both femoral fragments (Top-proximal and Bottomdistal) based on the well reconstructed cortical bone contact area in the Adams arch, which is the most important load bearing anatomical structure of the proximal femur.

The first reference model created was Model I (Fig. 2a), in which the lag screw placement after fracture reduction is "ideal" - anchored in the middle third of the femoral neck in the anteroposterior (AP) plane passing through the center of the femoral neck in the axial plane and extending to the subchondral area.

Model II (Fig. 2b) represents the same SHS lag screw position in Model I (i.e. the "ideal" position), but with a residual fracture gap between fragments, a condition that may occur if the proximal fragment is pushed into valgus during reduction.

In Model III (Fig. 2c), the lag screw is placed in the proximal third of the femoral neck in the AP plane and anchored subchondrally.

In Model IV (Fig. 2d), the lag screw is placed in the distal third of the femoral neck.

In Model V (Fig. 2e), the lag screw position is in the middle third of the femoral neck and anchored $10 \mathrm{~mm}$ away from the medial edge of the caput femoris.

The geometric model of the proximal femur was created from a series of CT images from a healthy female aged 65 years without visible arthritic changes of the joint. Segmentation of bone tissue was performed using the Mimics program (Materialise, Belgium), which was also used to create a 3D reconstruction model of the bone. A stable pertrochanteric fracture was created based on a reference clinical case. The geometric model of the proximal femur with the fracture line was then imported into the Abaqus program. The individual parts of the "broken" femur and the SHS were meshed by the C3D4 4-node element. The global element size was set from 1 to $2 \mathrm{~mm}$. The SHS model was imported into the Abaqus numerical FE program (Simulia, France) as a 3D model. Given the complexity of the simulations, the analyses were performed by simplifying the creation of lag screw models: parts were modeled without a thread profile. The lag screw threads were replaced by a smooth surface whose dimensions corresponded to the mean diameter of the given thread, and anchoring of screws into the bone was modeled by constrain conditions. We did not model different positions in the axial plane, insufficient depth of the screw more than $10 \mathrm{~mm}$ from the medial edge of the caput femoris. We did not evaluate different bone mineral density due to osteoporosis, the effect of cyclic loading or tip-apex distance (TAD) because of the prohibitive complexity of such modeling.

Material Models: For the purposes of this parametric study, a simplified material model of bone tissue was used. Bone was modeled as a non-homogeneous, isotropic and elasto-plastic material. The material properties for each CT image element were set according to the density of bone tissue $\rho\left[\mathrm{g} / \mathrm{cm}^{3}\right]$. This density was set according to the grey value in CT images. The same procedure was utilized to evaluate yield stress $\sigma_{y}[\mathrm{MPa}]$ as a function dependent upon the value of bone tissue density. In the FE analysis, bone tissue was also modeled as a material in which mechanical property degradation occurs after 
exceeding the load limit. Individual values that unambiguously described the behavior of the material model when exceeding $\sigma_{y}$ were reset according to bone density $\rho$. Stainless steel was used to produce the SHS (as an elasto-plastic material) with constants: Elastic Modulus E [MPa] 210 000; Poisson's ratio $\mu$ [-] 0.3; Ultimate tensile strength $R_{\mathrm{m}}[\mathrm{MPa}]$ 860; Yield stress $\sigma_{y}[\mathrm{MPa}] 690$. These parameters were provided by the manufacturer of SHS (Medin, Nove Mesto na Morave, Czech Republic).

Boundary conditions and loading. The focus of the study was to analyze the response of femoral bone tissue to loading in relationship to the exact position of the SHS lag screw. The numerical model was loaded by single force with a constant value that corresponds to hip joint loading during walking without support in a human weighing approximately $80 \mathrm{~kg}$, corresponding to a low-cycle high-stress load, which often occurs early after surgery when the patient cannot cooperate adequately with weight-bearing restrictions. The model only considered three main forces; those acting through the two dominant muscles - musculus iliopsoas and gluteal muscles, and the resulting reaction force of the hip joint. These external forces were applied to the FE model through the use of distributed coupling conditions, which allowed individual forces to be uniformly distributed over the bone tissue surface in an area that corresponds to the area of muscle insertion and femoral head/acetabulum contact (Fig. 5a).

The size of individual forces were $F_{\text {glut }}=642.3 \mathrm{~N}$, $F_{\text {iliop }}=376.4 \mathrm{~N}$ and $F_{\text {reac }}=1000 \mathrm{~N}[6,7]$. A typical friction coefficient of $f=0.3$ was used between femoral fragments, between the femur-hip screw shank and bone tissue, and between the hip plate and bone tissue. This interaction simulated a realistic situation in which there was no mutual penetration of individual parts, but it was permissible for them to be lying in contact against one another. Given the speed and stability of the simulations, the insertion of the hip screw into the bone was modeled with a TIE constraint condition (Fig. 5b). This specific type of condition represents the fixed connection of two parts in which the nodes of both contact parts have been fixed to each other, and wherein this constraint transmits the same value of displacement size from the master contact surface to the slave contact surface.

\section{Results}

With regard to the established objectives, the entire numerical parametric study was conceived as a static nonlinear contact task in which the output was the stress and strain distribution in individual parts of the FE model. The numerical FE analysis took the local mechanical properties

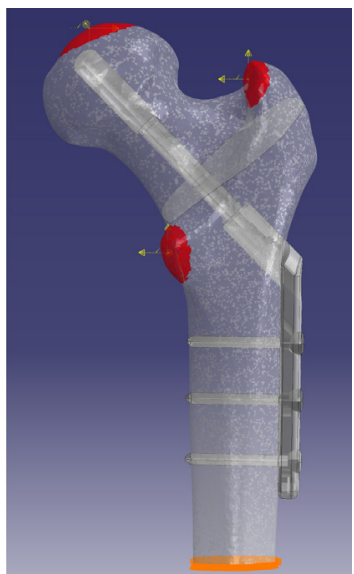

a)

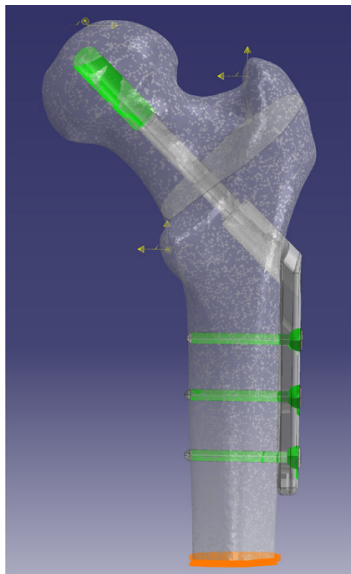

b)
Fig. 5 Boundary conditions and loading. a) illustration of the distributed coupling constraint condition used for the distribution of forces acting in the area of muscle insertions. b) illustration of tie bond in FE model.

of bone tissue into account and determined its response to external mechanical loading. To evaluate the results of the analyses, $\sigma_{\text {red }}$ was selected as the value of reduced stress, which is optimal for establishing the stress distribution in individual parts of the FE model. As bone tissue has different mechanical properties in tension or compression, a reduced stress $\sigma_{\text {red }}$ is appropriate for clear interpretation of the stress value and distribution in bone tissue.

The $\sigma_{\text {red }}$ values for the five experimental models are summarized in Table 1. Stress during loading was found to be considerable throughout the entire femur-SHS model, and the distal bone fragment (Bottom) was most stressed in the area around the free end of the femur model. The magnitude of this stress influenced the boundary conditions. In meeting the objectives of this study, it was important to assess the magnitude of stress in the top third of the model, where the SHS is placed.

From the results of FE simulations listed in Table 1, it was noted that stress in the whole femoral model and sliding screw with hip plate was significant during the tested loading. In all models the bone area with the highest loading force was found to be that of the lowermost cortical screw in the hip plate. Bone damage was also noted at the level of the fracture and the track, through which the sliding screw was placed. In all models except Model II, the highest loading of bone tissue of the proximal femoral fragment (Top) was seen to be at the lower edge of the femoral neck, at the level of the fracture plane. In this area, the proximal fragment leans against the distal fragment (Bottom). The maximum values of reduced stress $\sigma_{\text {red }}$ ranged from 83.1 (Model II) to 170.6 (Model I). 
Table 1 Table of the stress obtained maximal values of reduced stress $\sigma_{\text {red }}[\mathrm{MPa}]$ in individual parts of the numerical FE model of the proximal femoral fragments and sliding screw.

\begin{tabular}{lccccc}
\hline & $\begin{array}{c}\text { Top } \\
\text { (proximal fragment) }\end{array}$ & $\begin{array}{c}\text { Bottom } \\
\text { (distal fragment) }\end{array}$ & $\begin{array}{c}\text { Hip } \\
\text { plate }\end{array}$ & $\begin{array}{c}\text { Sliding } \\
\text { screw }\end{array}$ & $\begin{array}{c}\text { Cortical } \\
\text { screws }\end{array}$ \\
\hline Model I & $\sigma_{\text {red }}[\mathrm{MPa}]$ & $\sigma_{\text {red }}[\mathrm{MPa}]$ & $\sigma_{\text {red }}[\mathrm{MPa}]$ & $\sigma_{\text {red }}[\mathrm{MPa}]$ & $\sigma_{\text {red }}[\mathrm{MPa}]$ \\
\hline Model II & 170.6 & 192.9 & 436.5 & 435.3 & 693.1 \\
Model III & 83.1 & 168.5 & 703.8 & 716.6 & 695.5 \\
Model IV & 106.7 & 192.9 & 729.8 & 713.8 & 706.6 \\
Model V & 123.9 & 192.9 & 717.3 & 698.1 & 698.2 \\
\hline
\end{tabular}

a)

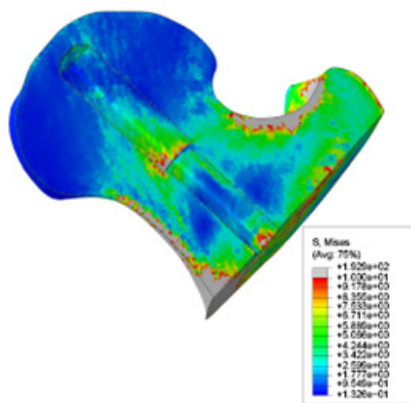

b)
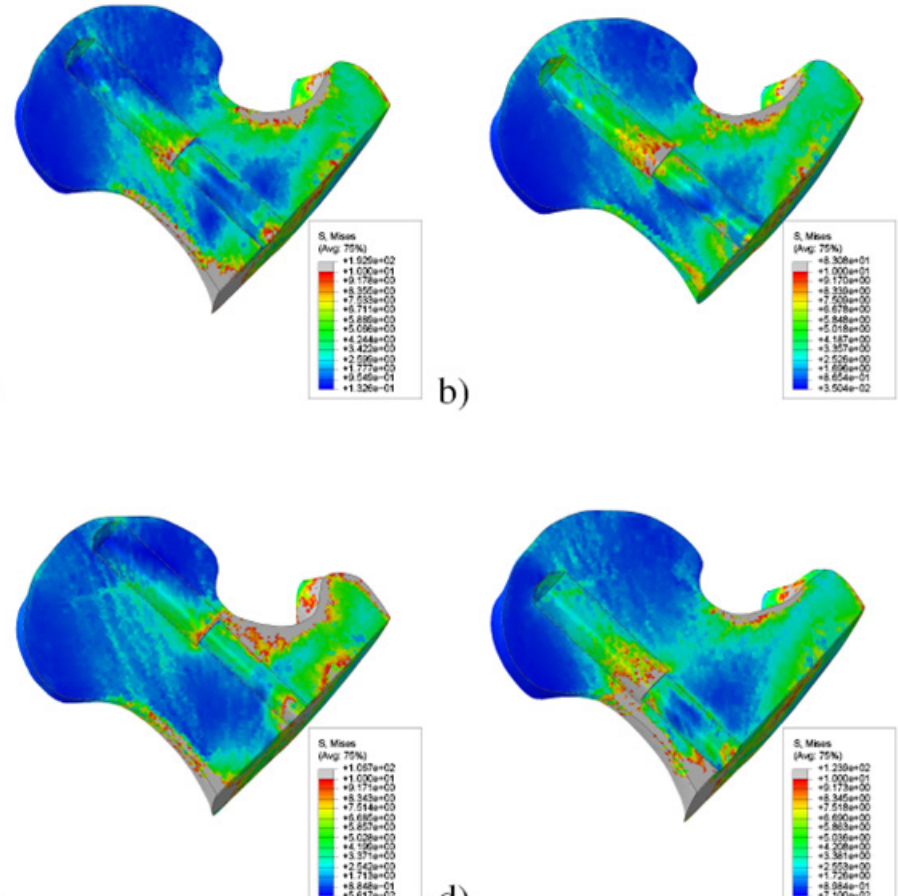

c)

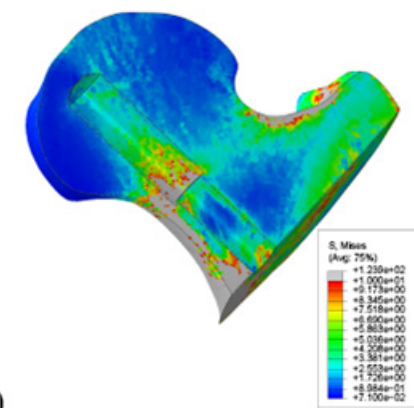

e)

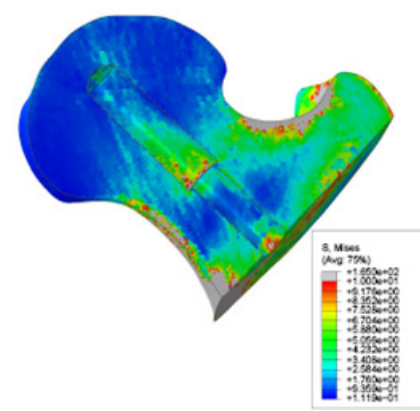

Fig. 6 The reduced stress distribution (von Mises stress) $\sigma_{\text {red }}[\mathrm{MPa}]$ in the cut of the proximal fragment (caput, femoral neck and part of trochanter major) in 5 model situations. The ideal position is a), where there is equal bone load in the head and neck. The location of the screw in the superior third of the femoral neck whith the highest risk for failure is depicted in c).

In contrast, in Model II, the maximum loading of the bone tissue was seen at the track in which the sliding screw is located, close to the fracture plane. Notably, all modeled situations showed clear damage of the bone tissue in the fracture plane associated with the opening through which the sliding screw passes (Fig. 6).

The type of stress distribution was found to be important in the response of bone tissue to external loading with various SHS locations. For successful osteosynthesis, it is important to achieve a uniform distribution of stress across the entire proximal femur. The optimum condition is shown in Fig. 6a, where the femoral neck is loaded equally in both its superior and inferior halves. The transfer of stress from the sliding screw to the caput femoris occurs mainly at the level of the border between the caput and femoral neck. In Model III and Model IV, the unequal transfer of loading from the inferior to the superior part of the femoral neck is visible in relation to the position of the lag screw (Fig. 6c, d). A similar situation is also seen in Model II, where a wedge-shaped gap is located at the fracture. As seen in Fig. 6b, stress is shifted to the superior part of the femoral neck, while the inferior edge transfers only a minimum load. At the same time stress increase is also seen in the area of caput femoris around the sliding screw thread. Another objective of the numerical FE analyses was to evaluate SHS stress (Fig. 7).

The resulting values of the reduced stress $\sigma_{\text {red }}$ are listed in Table 1 . The results clearly show that the loading of the 


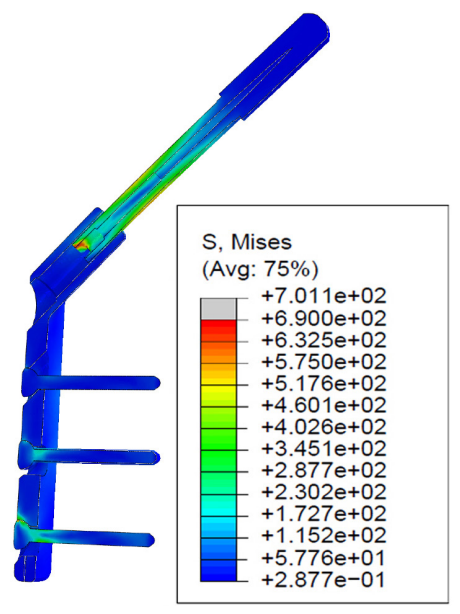

a)

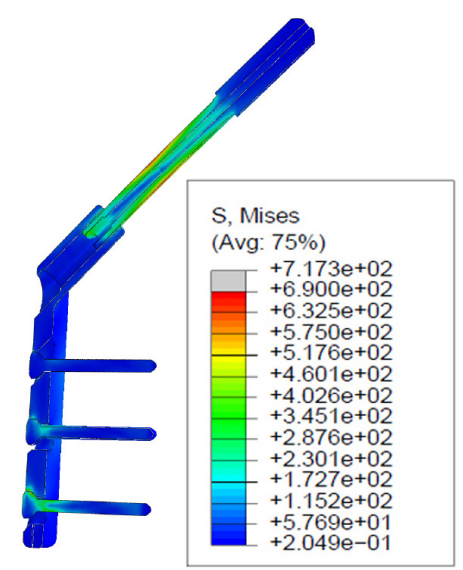

d)

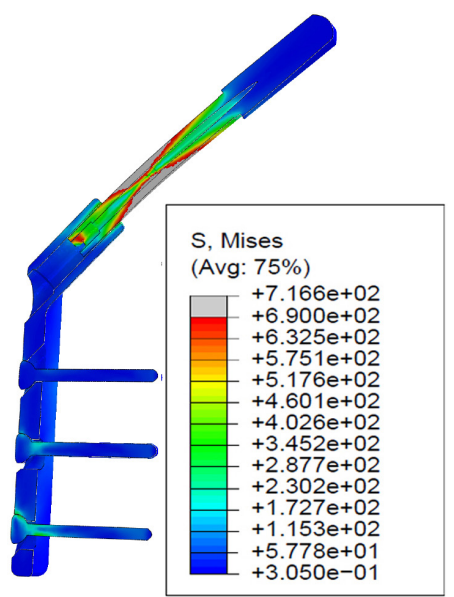

b)

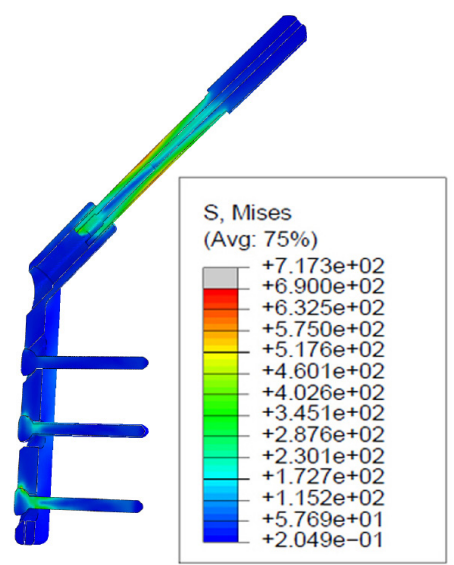

c)

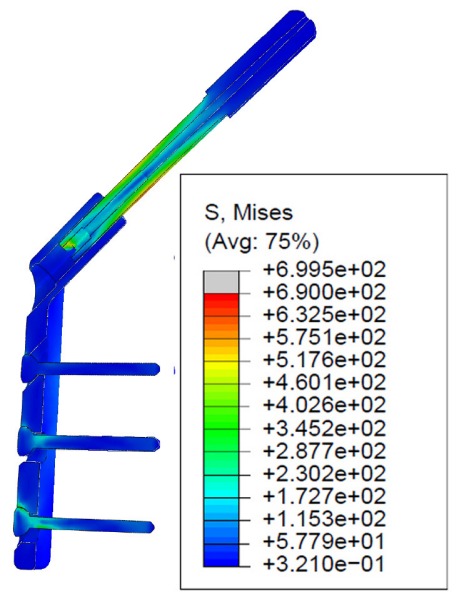

e)

Fig. 7 The equivalent stress distribution (von Mises stress) $\sigma_{\text {red }}[\mathrm{MPa}]$ in the Sliding Hip Screw in the 5 model situations analyzed. The highest risk of complications is shown in c) due to the stress distribution in the whole model. a) corresponds to Fig. 6a, and Model I. b) corresponds to Fig. 6b and Model II with wedge-shaped fracture gap between the bone fragments. c) corresponds to Fig. 6c, and Model III. d) corresponds to Fig. 6d, and Model IV. e) corresponds to Fig. 6e and Model V.

sliding screw (for the anticipated loading forces) was relatively high, and exceeded yield stress value $\sigma_{y}$. The values of the stresses on the hip plate and cortical screws were close to the yield stress; however, their magnitude is affected by the TIE coupling used for joining the cortical screws with the hip plate. The sliding screw presents a different situation. Stress is not affected by any couplings; however, the $\sigma_{\text {red }}$ was still higher than $\sigma_{y}$. In particular, screw placement in the superior third of the femoral neck (Model III with $\sigma_{\text {red }}=$ 729.8 $\mathrm{MPa}$ for the hip plate and $\sigma_{\text {red }}=713.8 \mathrm{MPa}$ for the sliding screw) increases the corresponding strain (by more than $63 \%$ in comparison to Model I with $\sigma_{\text {red }}=436.5 \mathrm{MPa}$ for the hip plate and $\sigma_{\text {red }}=435.3 \mathrm{MPa}$ for the sliding screw.

Our FE model results indicate that according to strain and stress distribution, all position of the SHS are acceptable except when it is located in the proximal third of the femoral neck (Model III).

\section{Discussion}

Many studies have dealt with the indications and the complications of the SHS. Appropriate technical implementation of the surgical steps and optimum implant position has been shown to be necessary for successful osteosynthesis [8]. As reported previously, common causes of failure of fixation are the following: fracture pattern unamenable to SHS treatment, poor fracture reduction, inappropriate screw location in the femoral head, bone quality issues such as osteoporosis and non-union [9, 10]. In a previous study reported by Hrubina et al. [11], different hip screw position based on clinical observation (308 cases) were 
examined utilizing FE analysis. The highest rate of failure that led to revision surgery at second stage was found to be in a small group of patients where the SHS was placed in the proximal third of the femoral neck. This position was considered as a surgical technical failure.

The ability to measure TAD on intraoperative images is not widely available, and is most often utilized on post-operative radiographic analysis of implant position. During the surgical procedure itself, the surgeon is often left to determine the acceptability of implant location by visual analysis. In this study we have tried to answer the question of how to proceed if the surgeon notices intra-operatively than the SHS lag screw is malpositioned. Should the screw be removed from the femoral neck and reintroduced in the "ideal" position (represented by Model I), and a large hollow track whose contribution to a possible fixation failure is unclear, left behind, or the lag screw accepted in its suboptimal location? The ideal position of the lag screw is known and was represented in this study by Model I. In this position, there is an equal stress and strain distribution in the proximal femur and implant, creating optimal conditions for fracture healing. In Model V, a high risk for cut-out of the lag screw was noted. The other analyzed situations (Model II, III, V) were seen to be suboptimal but with stress and strain values that were acceptable.

From the anatomical point of view, the exact reduction of the posteromedial cortical bone wall, also called the Adams arch, is crucial for the healing process of a stable pertrochanteric fracture. After appropriate anatomical reduction, the implant (SHS) helps maintain the fragments in this position until the healing process is sufficient and the bone can take charge of load bearing [12]. This time is thought to be a minimum of 6 weeks. Our study evaluated bone tissue response and stresses placed on the entire SHS fixation system based on variable lag screw placement during fixation

The situation is different in unstable fractures with no possibility of reducing Adams arc, and this is beyond the scope of this study. The anatomical and biomechanical situation is also different in proximal femoral fractures in coxarthrosis, but this type of fracture is very rare [13].

With the sliding effect of the SHS during the healing process, controlled impaction of the cortical and cancellous bone is possible during the postoperative rehabilitation of the patient and weight-bearing. Rotational stability of the fragments is maintained with a design characteristic of the implant as there is no possibility of the sliding screw rotating in hip plate. All above mentioned aspects are thought to prepare conditions for adequate fracture healing in the appropriate time. However, as the above detailed values indicate, the difference between individually evaluated models with the condition of a well reduced stable pertrochanteric fracture is not significant and, therefore, negligible from a clinical perspective. Therefore it can be said that if the primary introduction of SHS is not "ideal", but not in the proximal third of femoral neck and has sufficient anchorage, there is no need for a re-introduction of the screw during the primary surgery. This allows for a potentially considerable reduction in operative times and radiation load for the patient and surgeon. On the other hand, this is only one factor of a great many that can affect the results of the surgery. We cannot analyze the individual features of every patient such as fracture pattern, bone quality, the compatibility of the lag screw with the patient's particular anatomy, and patient compliance. The potential risk of SHS failure is also significantly increased by the cyclic loading of the femur which was not considered in the present study. We did not analyze the implant stiffness and elasticity.

Our experimental study has some strengths and limitations. Our study reports on the biomechanical analysis of five real-life clinical situations on the basis of a reproducible FE model that can be used for the analysis of other implants, such as the proximal femoral nail in the future.

Weaknesses include the limited number of modelled situations, and especially a lack of consideration of the axial plane. We did not include TAD analysis in our study as the effect of TAD on implant failure has been extensively researched in literature and is widely known. We also did not include the compression screw's effect, which has been reported to affect the stiffness of the whole system [14]. Only one femur with one bone density was utilized for our model. The effect of local bone density on mechanical failure after internal fixation of pertrochanteric fractures has been reported previously [15]. Nevertheless, we believe that, for the purposes of this parametric study, this simplification is negligible and in no way diminishes the informative value of the results or the conclusion expressed. The second major factor that significantly affects the interpretation of the results is the character of the entire study. The simulations were set as a static task, which is only capable of describing a single moment of loading and the systems response to the load, which does not have a constant value. This type of loading, however, may cause a gradual loosening of the lag screw from the caput femoris especially in osteoporotic bone, eventually leading to 
cut-out. From the above, it is evident that there is a need to maintain a certain degree of restraint when interpreting the results of our study, since the simulations did not reflect the real state of in vivo loading.

\section{Conclusion}

Our results indicate that excepting the one position where the lag screw is placed in the proximal third of the femoral neck, there is no significant difference between the other four analyzed SHS positions from the biomechanical point of view as long as the screw is placed centrally in the

\section{References}

[1] Douša, P., Čech, O., Weissinger, M., Džupa, V. "Trochanterické zlomeniny femuru" (Trochanteric femoral fractures), Acta Chirurgiae Orthopaedicae et Traumatologiae Czechoslovaca, 80(1), pp. 15-26, 2013. (in Czech)

[2] Skála-Rosenbaum, J., Bartoníček, J., Říha, D., Waldauf, P., Džupa, V. "Single-centre study of hip fractures in Prague, Czech Republic, 1997-2007", International Orthopaedics, 35(4), pp. 587-593, 2011.

https://doi.org/10.1007/s00264-010-0984-x

[3] Palm, H., Jacobsen, S., Sonne-Holm, S., Gebuhr, P. "Integrity of the Lateral Femoral Wall in Intertrochanteric Hip Fractures: An Important Predictor of a Reoperation", The Journal of Bone \& Joint Surgery, 89(3), pp. 470-475, 2007. https://doi.org/10.2106/JBJS.F.00679

[4] Arastu, M. H., Phillips, L., Duffy, P. "An unusual failure of a sliding hip screw in the immediate post-operative period", Injury Extra, 44(2), pp. 23-27, 2013.

https://doi.org/10.1016/j.injury.2012.10.011

[5] Baumgaertner, M. R., Curtin, S. L., Lindskog, D. M., Keggi, J. M. "The value of the tip-apex distance in predicting failure of fixation of peritrochanteric fractures of the hip", The Journal of Bone \& Joint Surgery, 77(7), pp. 1058-1064, 1995.

[6] Trabelsi, N., Yosibash, Z., Wutte, C., Augat, P., Eberle, S. "Patientspecific finite element analysis of the human femur - A double-blinded biomechanical validation", Journal of Biomechanics, 44(9), pp. 1666-1672, 2011.

https://doi.org/10.1016/j.jbiomech.2011.03.024

[7] Yosibash, Z., Katz, A., Ligrom, C. "Toward verified and validated FE simulations of a femur with a cemented hip prosthesis", Medical Engineering \& Physics, 35(7), pp. 978-987, 2013. https://doi.org/10.1016/j.medengphy.2012.09.007

[8] Bretherton, C., Parker, M. "Femoral Medialisation, Fixation Failures, and Functional Outcome in Trochanteric Hip Fractures Treated With Either a Sliding Hip Screw or an Intramedullary Nail From Within a Randomized Trial", Journal of Orthopaedic Trauma, 30(12), pp. 642-646, 2016. https://doi.org/10.1097/BOT.0000000000000689 axial plane and at an appropriate depth. Our results indicate that in fractures with a stable pattern, results may not depend on absolute precise positioning of the lag screw, and small deflections from the perfect position do not appear to significantly increase the risk of fixation failure and may be tolerable. It may not to be necessary to remove and re-introduce a lag screw as long as it is acceptable in the axial plane and it is not placed in the proximal third of the femoral neck, thus avoiding the bone loss incurred by a removal and re-introduction of the lag screw in an attempt to improve its position.

[9] Krischak, G., Dürselen, L., Röderer, G. "Versorgung pertrochantärer Femurfrakturen: Biomechanische Überlegungen" (Treatment of peritrochanteric fractures: Biomechanical considerations), Unfalchirurg, 114(6), pp. 485-490, 2011.

https://doi.org/10.1007/s00113-011-1976-z

[10] Necas, L., Hrubina, M., Cibula, Z., Behounek, J. Jr., Krivanek, S., Horak, Z. "Fatigue failure of the sliding hip screw - clinical and biomechanical analysis", Computer Methods in Biomechanics and Biomedical Engineering, 20(12), pp. 1364-1372, 2017. https://doi.org/10.1080/10255842.2017.1363192

[11] Hrubina, M., Horák, Z., Bartoška, R., Navrátil, L., Rosina, J. "Computational modeling in the prediction of Dynamic Hip Screw failure in proximal femoral fractures", Journal of Applied Biomedicine, 11(3), pp. 143-151, 2013. https://doi.org/10.2478/v10136-012-0017-8

[12] Reeve, J. "Role of cortical bone in hip fracture", BoneKEy Reports, 13(6), p. 867, 2017. https://doi.org/10.1038/bonekey.2016.82

[13] Hrubina, M., Skotak, M., Letocha, J. "Osteosyntéza zlomenin proximálního femuru metodou DHS v terénu koxartrózy" (Dynamic Hip Screw Osteosynthesis for Proximal Femoral Fractures in Patients with Coxarthrosis", Acta Chirurgiae Orthopaedicae et Traumatologiae Czechoslovaca, 82(5), pp. 364-368, 2015.

[14] Chang, C.-W., Chen, Y.-N., Li, C.-T., Peng, Y.-T., Chang, C.-H. "Role of the compression screw in the dynamic hip-screw system: A finite-element study", Medical Engineering \& Physics, 37(12), pp. 1174-1179, 2015. https://doi.org/10.1016/j.medengphy.2015.10.001

[15] Li, C., Xie, B., Chen, S., Lin, G., Yang, G., Zhang, L. "The effect of local bone density on mechanical failure after internal fixation of pertrochanteric fractures", Archives of Orthopaedics and Trauma Surgery, 136(2), pp. 223-232, 2016. https://doi.org/10.1007/s00402-015-2369-5 